\title{
APLIKASI E-SURAT SEBAGAI UPAYA PENDUKUNG TATA KELOLA PEMERINTAHAN DI DESA KUKUH, KERAMBITAN, TABANAN, BALI
}

\author{
${ }^{1)}$ I Putu Susila Handika, ${ }^{2)}$ I Kadek Susila Satwika \\ ${ }^{1)}$ Program Studi Teknik Informatika, STMIK STIKOM Indonesia \\ ${ }^{2)}$ Program Studi Sistem Komputer, STMIK STIKOM Indonesia \\ ${ }^{1,2}$ Jl. Tukad Pakerisan No. 97 Denpasar - Bali - Indonesia \\ E-mail : susila.handika@stiki-indonesia.ac.id,susila.satwika@stiki-indonesia.ac.id
}

\begin{abstract}
ABSTRAK
Sistem pemerintahan berbasis elektronik mengakibatkan pergeseran pola pikir konvensional menuju digitalisasi. Hal tersebut juga dilakukan oleh Desa Kukuh Kerambitan, Kabupaten Tabanan, Provinsi Bali. Untuk menunjang sistem pemerintahan berbasis elektronik tersebut, dilakukan penelitian pengembangan sistem informasi E-Surat di Desa Kukuh Kerambitan. Penelitian ini bertujuan untuk membantu perangkat desa dalam proses disposisi surat menjadi lebih cepat dan pembuatan laporan kegiatan juga menjadi lebih mudah. Penelitian ini dikembangkan menggunakan metode prototyping agar user dapat mengevaluasi aplikasi pada tahap desain. Aplikasi E-Surat dibangun berbasis web menggunakan bahasa pemrogramman PHP dan framework laravel. Dari hasil pengujian blackbox menunjukkan aplikasi E-Surat sudah berjalan sesuai dengan kebutuhan fungsional dan hasil pengujian usability juga menunjukkan sebagian besar rata-rata tiap pertanyaan bernilai lebih besar dari nilai tengah skala likert 1-7 yang berarti aplikasi dapat diterima oleh pengguna.
\end{abstract}

Kata Kunci: Sistem Informasi, Sistem Pemerintahan Berbasis Elektronik, E-Surat, Desa Kukuh Kerambitan.

\section{ABSTRACT}

The electronic based government system causes a change in the conventional mindset towards digitalization.. This was also done by Kukuh Kerambitan Village, Tabanan Regency, Bali Province. To Support the electronic based government system, research was carried out on the development of the E-Letter information system in Kukuh Kerambitan Village. This study aims to assist village officials in the letter disposition process to be faster and the process of making activity reports easier. This research was developed using the prototyping method so that users can evaluate the application at the design stage. The E-Letter application was built on a web basis using PHP programming language and laravel framework. From the results of the blackbox test, it shows that the E-Surat application has been running according to the functional needs and the results of the usability test also show that most of the average value of each question is greater than the middle value on the likert scale 1-7, which means the application can be accepted by the user.

Keyword: Information System, The Electronic Based Government system, E-Letter, Kukuh Kerambita Village.

\section{PENDAHULUAN}

Tata kelola pemerintahan yang baik (Good Governence) tentunya ditopang oleh pengelolaan pemerintahan yang baik dari level terbawah. Sesuai dengan Perpres No 95 tahun 2018 tentang Sistem Pemerintahan Berbasis Elektronik, maka perlu dilakukan pergeseran pola pikir konvensional menuju digitalisasi [1]. Hal ini juga diperlukan mengingat pandemi covid-19 yang melanda dunia sejak awal tahun 2020 lalu, yang mengakibatkan sebagian besar kegiatan masyarakat diwajibkan sedapat mungkin dilakukan tanpa perlu bertatap muka. Kondisi ini tentunya berdampak pula bagi kegiatan-kegiatan di berbagai organisasi pemerintahan. Bagi organisasi pemerintahan, pengurusan surat merupakan kegiatan yang sangat penting. Permasalahan yang terdapat dalam pengurusan surat adalah keterlambatan dalam penyampaian surat, kekeliruan dalam mengarahkan surat ke unit kerja yang dituju sesuai kepentingan surat dan kebocoran informasi yang terdapat dalam surat tersebut [2]. Perkembangan teknologi informasi menuntut pengguna informasi mendapatkan arsip maupun informasi yang terdapat di dalamnya secara cepat, tepat dan aman [3]. Demi menciptakan sebuah sistem pelayanan yang lebih efektif, efisien, dan tepat sasaran, kinerja pelayanan secara administrasi harus 
diperhatikan dengan baik oleh pemerintahan Desa. Improvisasi terhadap perkembangan dunia teknologi juga diperlukan guna memanfaatkan fungsi teknologi dengan positif [4].

Permasalahan serupa juga terjadi di Kantor Kepala Desa Kukuh, Kecamatan Kerambitan, Kabupaten Tabanan, Bali. Dalam melakukan administrasi pengarsipan surat masuk, kegiatan berawal dari bagian umum. Surat yang masuk ke Bagian Umum akan diberikan ke Perbekel Desa yang akan memilah jenis surat masuk tersebut. Kegiatan selanjutnya yang dilakukan oleh Perbekel Desa adalah membuat disposisi kepada pihak terkait sesuai surat yang masuk tersebut. Dalam membuat disposisi, Perbekel Desa menggunakan selembar kertas dan kemudian diberikan kepada Bagian Umum untuk didistribusikan sesuai isi disposisi yang dibuat. Permasalahan yang terjadi adalah terkadang pihak terkait tidak ada di tempat karena tentunya kegiatan di kantor Desa seringkali mengharuskan seorang karyawan untuk melaksanakan dinas luar padahal surat tersebut harus segera ditindaklanjuti, hal ini tentunya menyebabkan keterlambatan penyampaian informasi.

Permasalahan lain yang muncul akibat masih dilakukannya kesulitan pengarsipan surat secara manual adalah arsip surat yang ada dan membutuhkan tempat penyimpanan khusus. Seringkali terjadi kehilangan surat karena surat yang dimiliki hanya berupa surat fisik saja. Permasalahan lain yang terjadi adalah dalam hal pelaporan kegiatan. Setelah kegiatan selesai dilakukan, maka pihak terkait diwajibkan untuk membuat laporan kegiatan. Selama ini, pelaporan kegiatan hanya dilakukan melalui whatsapp. Hal ini menyebabkan pelaporan kegiatan kurang tertata rapi dan seringkali tidak terdokumentasi sehingga menyebabkan evaluasi terhadap kegiatan yang telah dilakukan menjadi tidak optimal.
Untuk menyelesaikan permasalahanpermasalahan tersebut, maka dibangun sebuah sistem pengarsipan surat (E-Surat) di Desa Kukuh. Melalui pembuatan sistem ini, maka mekanisme pengarsipan surat akan berubah dari berbasis berkas ke digital. Surat yang diterima pada Bagian Umum akan dipindai sehingga surat tersebut telah memiliki salinan dalam bentuk softcopy. Softcopy surat tersebut kemudian dikirim ke Perbekel Desa untuk kemudian dibuatkan disposisi ke pihak terkait. Pihak yang mendapat disposisi dapat mengakses surat tersebut melalui aplikasi yang dibuat. Aplikasi ini dapat diakses melalui perangkat elektronik seperti handphone atau komputer, sehingga surat yang penting dapat tersampaikan dengan cepat. Setelah kegiatan dilaksanakan maka laporan kegiatan dapat dibuat dan disimpan pada aplikasi E-Surat yang dibuat. Sehingga seluruh surat masuk, disposisi, dan laporan dapat terdokumentasi dengan baik yang berimbas pada peningkatan pelayanan Desa Kukuh.

Beberapa aplikasi E-Surat telah dibuat oleh beberapa peneliti yang berbeda, seperti pada penelitian pembuatan E-Surat pada Perangkat Desa di Desa Menturus Kudu Jombang yang berfokus pada pembuatan aplikasi permohonan surat warga untuk mempermudah warga dalam pengurusan surat yang dibutuhkan [4]. Penelitian sejenis terkait pengarsipan surat masuk dan surat keluar telah dilakukan oleh Putri Imelda Sari melalui penelitian berjudul Sistem Informasi Pengarsipan Surat Masuk dan Surat Keluar di Notaris Debora Ekawati Lukman Dadali, SH [5] serta Penelitian berjudul Sistem Pengarsipan Surat Masuk dan Surat Keluar pada Kantor Kecamatan Pringkuku [6] dan penelitian terkait terakhir dilakukan pada penelitian yang berjudul Sistem Pengarsipan Data Surat Masuk dan Surat Keluar pada Polrestabes Semarang [7]. Perbedaan penelitian ini dengan ketiga 
penelitian sebelumya adalah pada penelitian ini selain membuat sebuah aplikasi pencatatan surat masuk dan surat keluar, juga terdapat fasilitas pembuatan laporan kegiatan terkait surat yang telah ditindaklanjuti oleh perangkat desa. Hal ini perlu dilakukan agar seluruh kegiatan dari surat masuk sampai pelaporan pertanggung-jawabannya terdokumentasi dengan baik.

Berdasarkan hal-hal tersebut, maka penelitian ini dibuat untuk menghasilkan sebuah aplikasi E-Surat yang akan digunakan di Kantor Desa Kukuh, Kerambitan, Tabanan, Bali. Aplikasi E-Surat dibagun berbasis website yang tujuan untuk mempermudah dalam pengaksesannya dengan menggunakan bahasa pemrograman PHP dan Framework Laravel. Untuk memastikan keseluruhan fungsionalitas aplikasi telah berjalan sesuai tujuan, maka dilakukan pengujian menggunakan blackbox testing dan usability testing.

\section{METODE}

\section{Kerangka Kerja Penelitian}

Pada penelitian ini, metode prototyping dipilih sebagai metode pengembangan perangkat lunak. Metode ini dipilih agar user dapat mengevaluasi prototipe dari aplikasi ESurat. Dengan demikian, kesalahan proses bisnis pada saat proses development akan dapat diminimalisir.

Gambar 1 menunjukkan proses rancang bangun aplikasi E-Surat di Desa Kukuh Kerambitan. Pada tahap pertama, informasi yang dibutuhkan untuk pengembangan sistem dikumpulkan melalui proses wawancara denga user dan survey lokasi. Tahap selanjutnya adalah pembuatan desain aplikasi berupa Data Flow Diagram (DFD) dan Pysical Data Model $(P D M)$. Hasil dari tahap kedua ini adalah dokumentasi desain. Setelah melalui tahap desain, tahap selanjutnya adalah adalah pembuatan prototipe sistem dari hasil analisa kebutuhan dan desain yang telah disepakati sebelimnya. Prototype tersebut akan dievaluasi oleh user selama prototype tersebut belum sesuai dengan kebutuhan user. Dengan adanya perulangan pada proses pengembangan prototype, diharapkan pada saat proses pengembangan sistem, terjadi perubahan proses bisnis yang sangat kecil bahkan tidak ada perubahan. Dengan demikian, proses pengembangan akan menjadi lebih cepat. Jika prototype sudah sesuai dengan kebutuhan dan desain, proses akan dilanjutkan dengan pengembangan aplikasi lalu pengujian aplikasi. Jika semua proses telah dilalui, proses terakhir adalah melakukan pemeliharaan terhadap aplikasi yang telah dihasilkan.

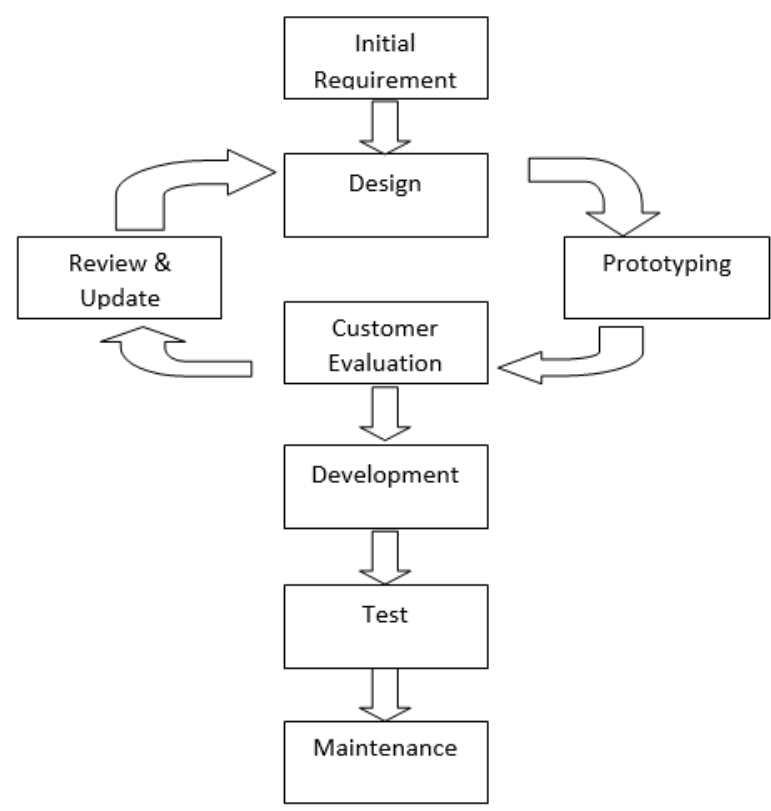

Gambar 1. Metode Prototyping.

\section{HASIL}

\section{Analisa Kebutuhan}

Tahap pertama dari proses pengembangan sistem adalah analisa kebutuhan. Output dari analisa kebutuhan ini adalah kebutuhan fungsional sistem E-Surat. Analisa kebutuhan didapat dengan cara melakukan proses wawancara langsung dengan user yang terlibat pada proses bisnis. Tabel 1 menunjukkan hasil analisa kebutuhan untuk mengembangkan 
aplikasi E-Surat.

Tabel 1. Analisa Kebutuhan

\begin{tabular}{cl}
\hline No & \multicolumn{1}{c}{ Kebutuhan } \\
\hline 1 & $\begin{array}{l}\text { Aplikasi dapat menyimpan surat } \\
\text { data surat masuk beserta file surat } \\
\text { masuk }\end{array}$ \\
\hline 2 & $\begin{array}{l}\text { Aplikasi dapat melakukan proses } \\
\text { disposisi surat masuk ke pegawai } \\
\\
\text { yang menjabat dibawahnya }\end{array}$ \\
\hline 3 & File surat dapat didownload dan \\
& $\begin{array}{l}\text { user yang berhak untuk melakukan } \\
\text { proses download adalah bagian } \\
\text { sekretaris }\end{array}$ \\
\hline 4 & $\begin{array}{l}\text { Aplikasi dapat menyimpan laporan } \\
\text { kegiatan atas surat yang masuk }\end{array}$ \\
\hline 5 & $\begin{array}{l}\text { Aplikasi dapat menampilkan } \\
\text { laporan surat masuk dan surat } \\
\text { keluar }\end{array}$ \\
\hline 6 & $\begin{array}{l}\text { Aplikasi dapat menghapus file-file } \\
\text { surat yang yang telah tersimpan } \\
\text { dalam jangka waktu lama atau yang } \\
\text { telah ditentukan. }\end{array}$
\end{tabular}

\section{Physical Data Model}

Physical Data Model (PDM) adalah gambaran dari sejumlah tabel yang menggambarkan data serta hubungan beberapa entitas yang memiliki nama unik [8]. PDM dari aplikasi E-Surat ditunjukkan pada Gambar 2.

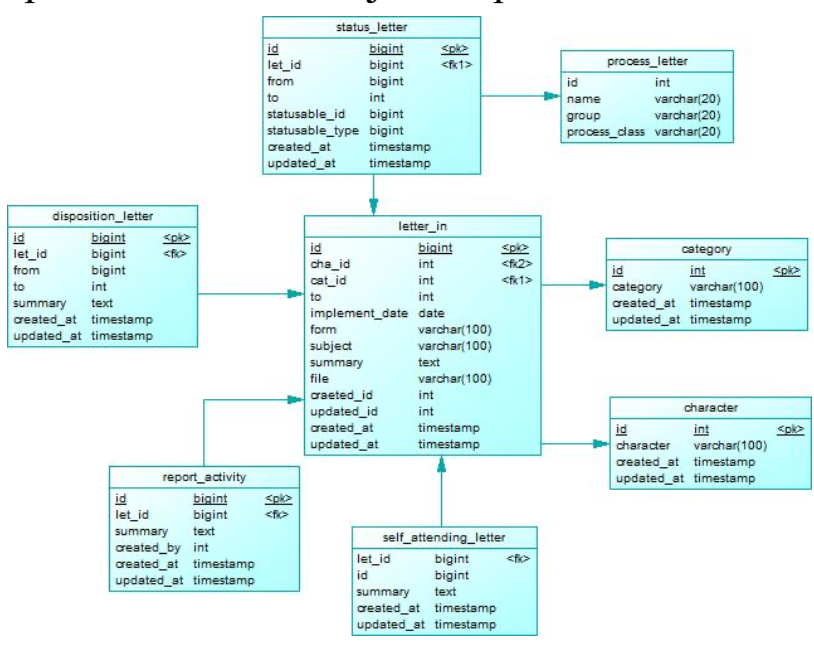

Gambar 2. Physical Data Model Aplikasi E-Surat.
Data Flow Diagram (DFD)

Data Flow Diagram (DFD) merupakan gambaran atau model aliran data dalam sebuah sistem informasi [9]. Gambar 3 menunjukkan DFD Level Konteks aplikasi E-Surat.

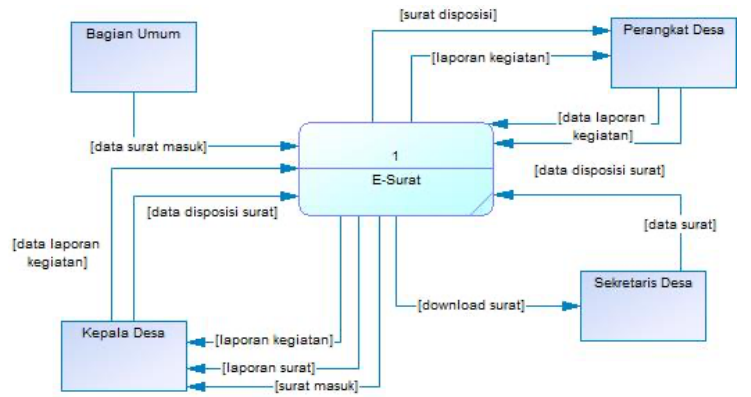

Gambar 3. Data Flow Diagram Level Konteks E-Surat.

Entitas yang terhibung dalam aplikasi ESurat antara lain, Kepala Desa, Bagian Umum, Perangkat Desa, dan Sekretaris Desa. Entitas Bagian Umum merupakan entitas yang bertugas untuk menginputkan surat masuk. Entitas Kepala Desa mendapatkan informasi surat masuk yang telah diinputkan oleh Bagian Umum, Kepala desa dapat memproses surat masuk untuk diri sendiri atau dapat mendisposisikan surat yang masuk ke perangkat desa di Bawahnya. Kepala Desa juga mendapatkan laporan surat masuk serta laporan kegiatan dari perangkat desa lainnya. Entitas Perangkat Desa mendapatkan disposisi surat dari Kepala Desa, perangkat desa dapat melaporkan kegiatan dari surat masuk tersebut kedalam sistem E-Surat. Entitas Sekretaris Desa bertugas untuk mendokumentasikan surat masuk.

\section{Aplikasi E-Surat}

Halaman pertama pada aplikasi E-Surat adalah halaman login. Halaman login dibuat untuk memberikan batasan kepada pihak yang tidak berkepentingan agar tidak bisa mengakses dan mengolah data. Form login ditunjukkan pada Gambar 4. 


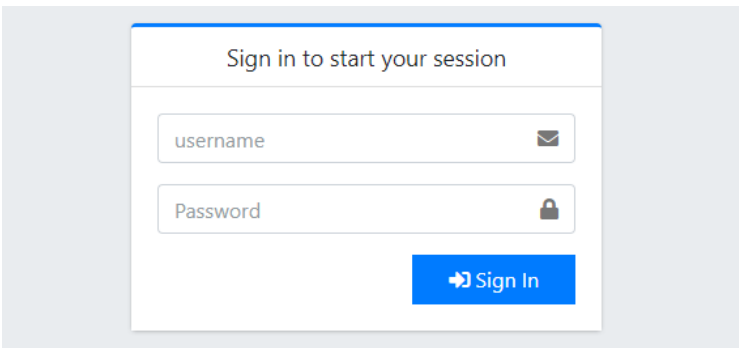

Gambar 4. Form Login.

Setelah melakukan login, aplikasi akan menampilkan halaman dashboard. Pada halaman dashboard, terdapat menu surat masuk dan disposisi surat. Halaman dashboard ditunjukkan pada Gambar 5.

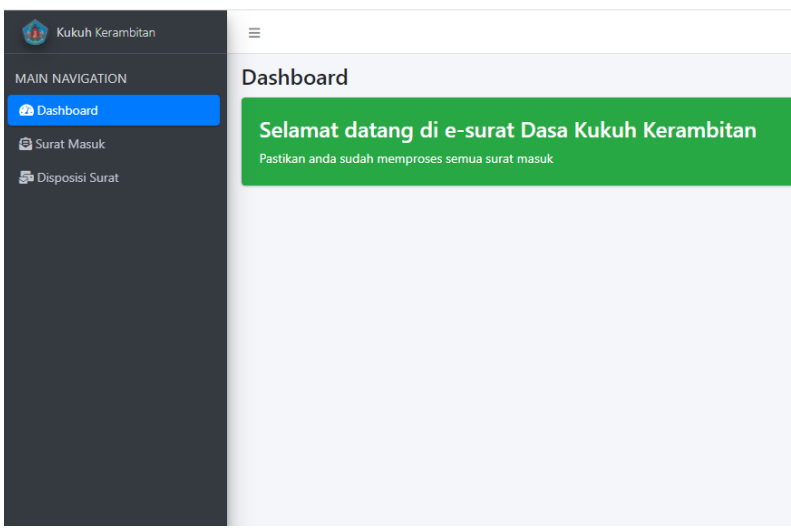

Gambar 5. Halaman Dashboard.

Menu surat masuk berfungsi untuk mengelola surat masuk mulai dari melihat daftar surat masuk, menambah surat masuk, dan melihat surat masuk yang telah dibuat. Menu surat masuk ditunjukkan pada Gambar 6.

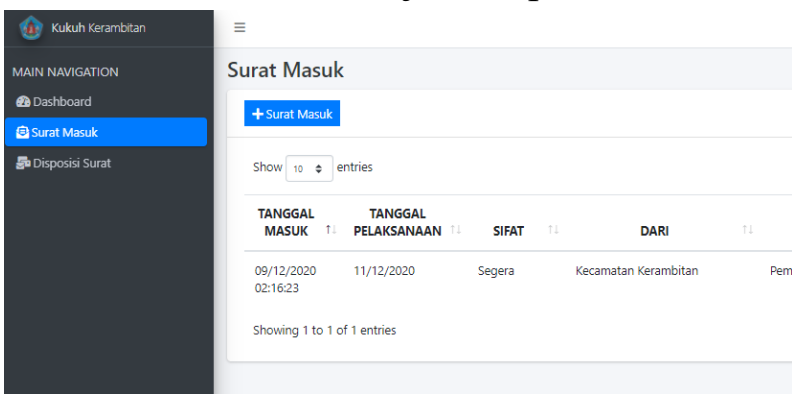

Gambar 6. Menu Surat Masuk.

Form tambah surat masuk digunakan untuk memasukkan data surat masuk serta mengupload file surat masuk yang telah discan. Form surat masuk ditunjukkan pada Gambar 7.

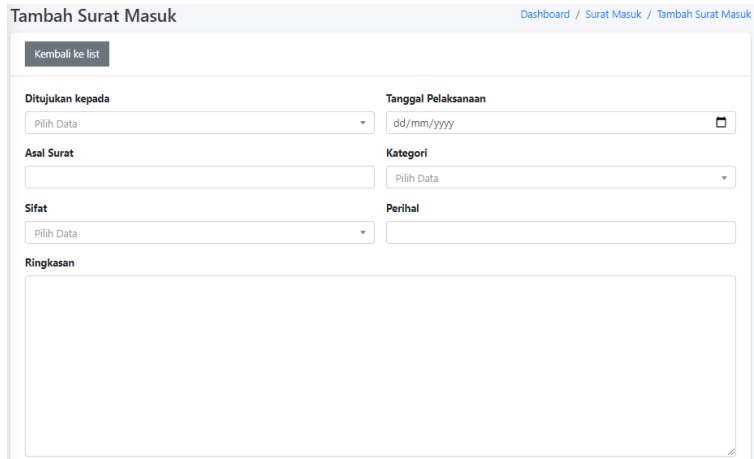

Gambar 7. Halaman Tambah Surat Masuk.

Form proses surat berfungsi untuk memproses surat masuk. Pada form proses surat, terdapat dua pilihan proses yaitu disposisi atau hadiri sendiri. Jika proses yang dipilih adalah disposisi, maka wajib diinputkan kepada siapa surat akan didisposisikan. Jika proses yang dipilih adalah hadiri sendiri, maka secara otomatis surat akan diberikan kepada pengguna yang login pada saat itu. Form proses surat dapat dilihat pada Gambar 8.

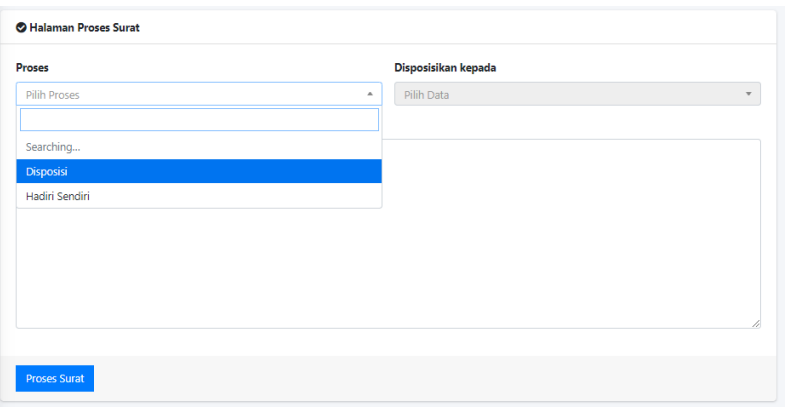

Gambar 8. Proses Surat.

Perangkat desa dapat melaporkan hasil kegiatan yang terdapat pada surat masuk melalui form laporan kegiatan yang ditunjukkan pada Gambar 9.

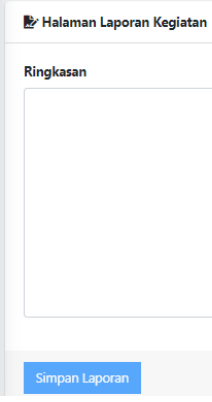

Gambar 9. Laporan Kegiatan. 


\section{Pengujian Fungsional (Blackbox Testing)}

Dasar dari pengujian fungsional adalah kebutuhan yang didapat dari proses perencanaan. Pengujian fungsional blackbox bertujuan untuk memastikan semua kebutuhan sistem dapat berjalan dengan baik dengan cara menjalankan semua modul pada aplikasi dihadapan user. Jika modul yang dijalankan diterima oleh user, maka diberikan status OK. Tabel 2 menunjukkan hasil pengujian fungsional blackbox.

Tabel 2. Hasil Pengujian Fungsional Blackbox.

\begin{tabular}{|c|c|c|}
\hline No & Kebutuhan & Status \\
\hline 1 & $\begin{array}{l}\text { Aplikasi dapat } \\
\text { menyimpan surat data } \\
\text { surat masuk beserta file } \\
\text { surat masuk }\end{array}$ & $\mathrm{OK}$ \\
\hline 2 & $\begin{array}{l}\text { Aplikasi dapat melakukan } \\
\text { proses disposisi surat } \\
\text { masuk ke pegawai yang } \\
\text { menjabat dibawahnya }\end{array}$ & $\mathrm{OK}$ \\
\hline 3 & $\begin{array}{l}\text { File surat dapat } \\
\text { didownload dan user yang } \\
\text { berhak untuk melakukan } \\
\text { proses download adalah } \\
\text { bagian sekretaris }\end{array}$ & $\mathrm{OK}$ \\
\hline 4 & $\begin{array}{l}\text { Aplikasi dapat } \\
\text { menyimpan laporan } \\
\text { kegiatan atas surat yang } \\
\text { masuk }\end{array}$ & $\mathrm{OK}$ \\
\hline 5 & $\begin{array}{l}\text { Aplikasi dapat } \\
\text { menampilkan laporan } \\
\text { surat masuk dan surat } \\
\text { keluar }\end{array}$ & $\mathrm{OK}$ \\
\hline 6 & $\begin{array}{l}\text { Aplikasi dapat } \\
\text { menghapus file-file surat } \\
\text { yang yang telah tersimpan } \\
\text { dalam jangka waktu lama } \\
\text { atau yang telah } \\
\text { ditentukan. }\end{array}$ & $\mathrm{OK}$ \\
\hline
\end{tabular}

\section{Usability Testing}

Usability testing merupakan salah satu metode pengujian dimana fokus dari pengujiannya adalah kenyamanan pada saat penggunaan sistem. Usability testing bertujuan untuk mendapatkan feedback dari pengguna [10]. Metode USE merupakan salah satu metode untuk menguji usabilty testing. Metode USE menilai 3 aspek yaitu efisiensi, efektivitas, dan kepuasan. Pada metode USE terdapat 30 point pertanyaan untuk mengukur tingkat persetujuan user terhadap aplikasi yang telah dibuat denga mengunnakan skala likert 1-7. Pengujian usability dilakukan dengan sampel semua perangkat desa yang terdapat di Desa Kukuh dengan total perangkat desa 13 Orang.

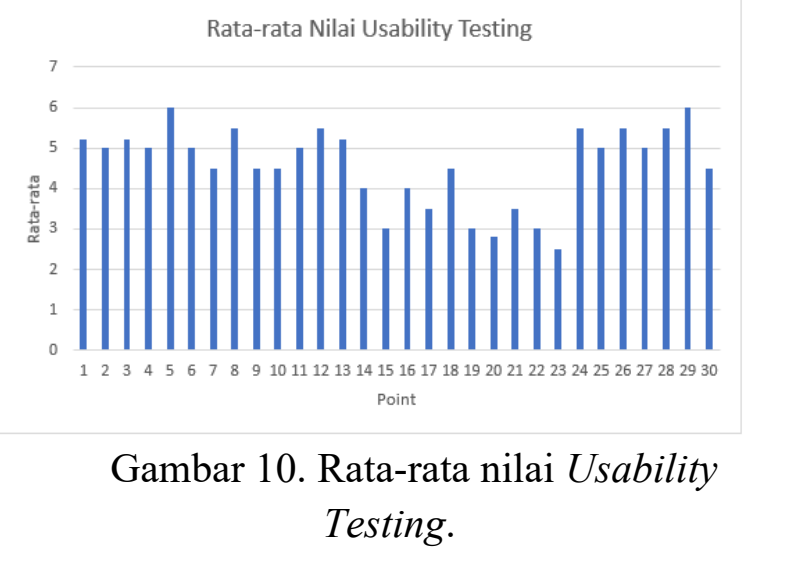

Gambar 10 menunjukkan hasil pengujian Usability. Dari hasil pengujian tersebut point nomer 15, 17, 19, 20, 21, 22, 23 mendapatkan rata-rata dibawah nilai tengah skala likert dimana point tersebut mengacu pada elemen ease of use dan ease of learning. Hasil ini disebabkan karena beberapa perangkat desa yang tidak melek terhadap teknologi yang mengakibatkan pengetahuan terhadap hal baru terutama pengetahuan bidang teknologi masih dibawah rata-rata. Dengan adanya pelatihan dan pendampingan penggunaan program secara teratur, diharapkan dapat membantu perangkat desa dalam penggunaan aplikasi. Secara garis besar hasil pengujian usability menunjukkan rata-rata diatas tengah skala likert 1-7 yang 
berarti aplikasi E-Surat dapat diterima dengan baik oleh pengguna.

\section{KESIMPULAN}

Dari hasil penelitian yang telah dilakukan, aplikasi E-Surat dapat digunakan dengan baik oleh perangkat Desa Kukuh untuk mengelola surat masuk, disposisi surat, sampai dengan pembuatan laporan kegiatan. Hasil pengujian blackbox menunjukkan kalau aplikasi dapat berjalan sesuai dengan kebutuhan dan hasil pengujian usability menunjukkan sebagian besar rata-rata tiap pertanyaan bernilai lebih besar dari nilai tenah skala likert 1-7 yang berarti aplikasi dapat diterima oleh pengguna, walaupun perlu dilakukan pendampingan secara berkala terhadap perangkat desa karena beberapa masih terkendala dengan teknologi baru

\section{DAFTAR PUSTAKA}

[1] "Peraturan Presiden Republik Indonesia Nomor 95 Tahun 2018 tentang Sistem Pemerintahan Berbasis Elektronik," Jakarta, 2018.

[2] E. A. Rachma, "Penggunaan Aplikasi ESurat SIKD (Sistem Informasi Kearsipan Dinamis) Dalam Pengelolaan Arsip Elektronik Untuk Mendukung EGoverment Di Badan Arsip dan Perpustakaan Kota Srabaya," J. Pendidik. Adm. Perkantoran, 2015.

[3] A. D. L. Tarigan and J. Jumino, "Pemanfaatan Aplikasi E-Surat Dalam Mendukung Pengelolaan Arsip Dinamis Aktif Di Dinas Kearsipan Dan Perpustakaan Provinsi Jawa Tengah," $J$. Ilmu Perpust., vol. 7, no. 3, pp. 71-80, 2018.

[4] H. Sucipto, A. Mujianto, C. Mahsuri, M. Ali, and Mahfudiyanto;" "Implementasi Aplikasi E-Surat Pada Perangkat Desa," pp. 34-41, 2020.
[5] P. I. Sari, "Sistem Informasi Pengarsipan Surat Masuk Dan Surat Keluar Di Notaris Debora Ekawati Lukman Dadali, Sh," Sekol. Tinggi Manaj. Inform. Dan Komput. Gici Batam, 2018.

[6] D. Anggraeni and S. Iriani, "Sistem Informasi Pengarsipan Surat Masuk Dan Surat Keluar Pada Kantor Kecamatan Pringkuku," Indones. J. Netw. Secur., no. 24, pp. 1-4, 2013.

[7] oky D. Prasetya, "Sistem Informasi Pengarsipan Data Surat Masuk Dan Program Studi Sistem Informasi Fakultas Ilmu Komputer Universitas Dian Nuswantoro Semarang," Sist. Inf. Pengarsipan Data Surat Masuk Dan Surat Kelur Pada Polrestabes Semarang, 2010.

[8] K. Octafiani, "Aplikasi Android Untuk Fasilitas Antar Jemput Siswa SD," $J$. Manaj. Inform., vol. 8, pp. 35-43, 2018.

[9] I. Solikhin, M. Sobri, and R. Saputra, "Sistem Informasi Pendataan Pengunjung Perpustakaan (Studi kasus : SMKN 1 Palembang)," J. Ilm. Betrik, vol. 9, no. 03, pp. 140-151, Nov. 2018.

[10] D. A. Fatah, "Evaluasi Usability dan Perbaikan Desain Aplikasi Mobile Menggunakan Usability Testing dengan Pendekatan Human-Centered Design (HCD)," Rekayasa, vol. 13, no. 2, pp. 130-143, Aug. 2020. 